\title{
Academic Library Planning: Rationality, Imagination, and Field Theory in the Work of Walter Netsch-A Case Study
}

\section{William G. Jones}

Architect Walter Netsch is responsible for the design of fifteen library buildings, including such major works as the University of Chicago's Joseph Regenstein Library and Northwestern University's main library. Netsch developed a principle for ordering the design elements in some of these buildings that he has termed "field theory." This paper discusses how field theory principles were applied in two Netsch buildings, how he used a complicated geometry in a third, and how the planning committee modified the application of the "field" in one of those buildings.

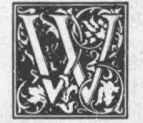

alter A. Netsch, Jr., design partner for Chicago's Skidmore, Owings, and Merrill Architectural Firm, designed fifteen library buildings during his career. Two of them were major research libraries and were built for Northwestern University (1969) and the University of Chicago (1970).

Netsch gained national recognition as an innovative and imaginative architect through such assignments as the master plan for the U.S. Air Force Academy at Colorado Springs (1962) and the University of Illinois at Chicago Circle (1965).

He designed other libraries, both public and academic, including those for Wells College in Aurora, New York (1968) and Texas Christian University (1981). The University of Illinois at Chicago Circle design included a large library building to be constructed in three phases, although this campus library was designed primarily to serve an undergraduate enrollment. (Only two phases were completed.) ${ }^{1}$

In many of his buildings Netsch em- ployed a design system that he labeled "field theory," a method for developing the layout on both large and small scales through the elaboration of a geometric figure. This article explains what field theory is, how Netsch used it in one of his earlier buildings, how he used geometric figures (but not according to field theory principles) in Northwestern University's main library, and how he applied the theory in the Science-Engineering Library (SEL, 1977) at Northwestern University. It also shows how the SEL planning committee changed Netsch's proposed design, and the effect these changes had on the aesthetic and functional dimensions of the building.

Architectural Record ${ }^{2}$ defined field theory as follows:

Once the programmatic needs and site requirements are organized into a generalized plan that works, various geometric fields are tested and an appropriate one applied. The selected field provides a continuous proportional system with infinite mathematical variations. As in contemporary painting, sculpture and music;

William G. Jones is Acting University Librarian at the University of Illinois, Chicago, Illinois 60680. 
continuity, ambiguity, overlapping, scale change, lattice, pattern and shape are constant ordering elements.

The primary ordering systems in Netsch's Field Theory are the combinations (or orthogonal right angle) patterns and diagonal (angular) patterns most often defined by rotating the square. The combination of patterns that results from this geometrical game becomes the field. The variety of patterns that can be produced by this process results in infinite opportunities to find a field that will give order to the preliminary organization of building elements.

A "rotated square" looks like this:

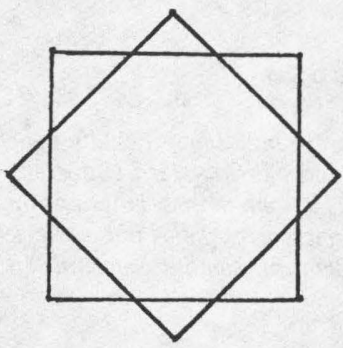

It can be elaborated to look like this:

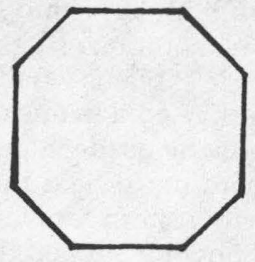

And like this: ${ }^{3}$

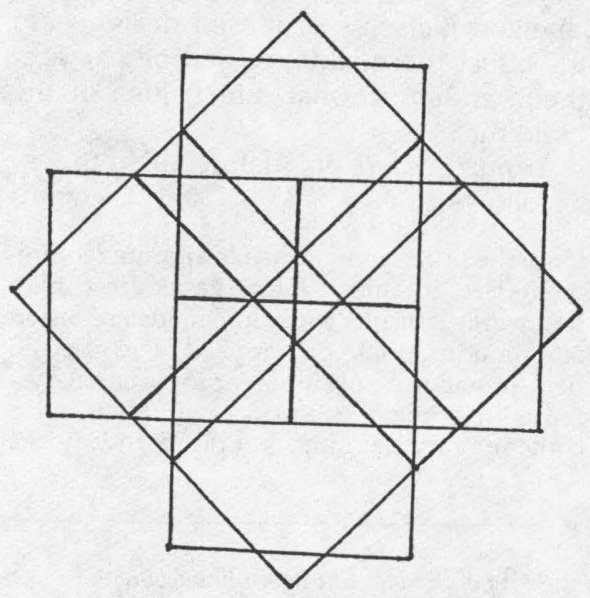

A schematic layout for a field theory building based on the rotated square is the Behavioral Sciences Building (BSB) at the University of Illinois at Chicago (1965). (See figure 1 and photograph 1.) The building contains offices, classrooms, lecture halls, and a cafeteria, incorporating such varied features as winding staircases, galleries, and atria. (See photo-

\section{"Although stylistically elegant, us- ers complain that the complicated layout, extensive use of interior corri- dors, and inadquate lighting lead to a building that prevents users from finding their way within it."}

graphs $2,3,4$.) Through the elaboration of the geometric figures contained within the rotated square, Netsch created a building of great variety, both geometric and symmetric. Although stylistically elegant, users complain that the complicated layout, extensive use of interior corridors, and inadequate lighting lead to a building that prevents users from finding their way within it.

Northwestern University's Main Library (1969) was built to replace the older Deering Library with a research library serving faculty, graduate students, and undergraduates. It houses the library's social sciences and humanities collections, the library's administrative offices, the technical processing operations for all Evanston campus libraries, and it contains such specialized service units as government publications, reference, curriculum collection, the Melville J. Herskovits Library of Africana, and a 60,000 volume noncirculating collection (the Core Library) designed primarily for undergraduate use.

The Northwestern Library possesses three stack towers raised over the services floor. The services floor contains administration, circulation, periodicals, reference, and technical processing. A service core containing elevators and stairs links the towers and provides vertical transporta- 


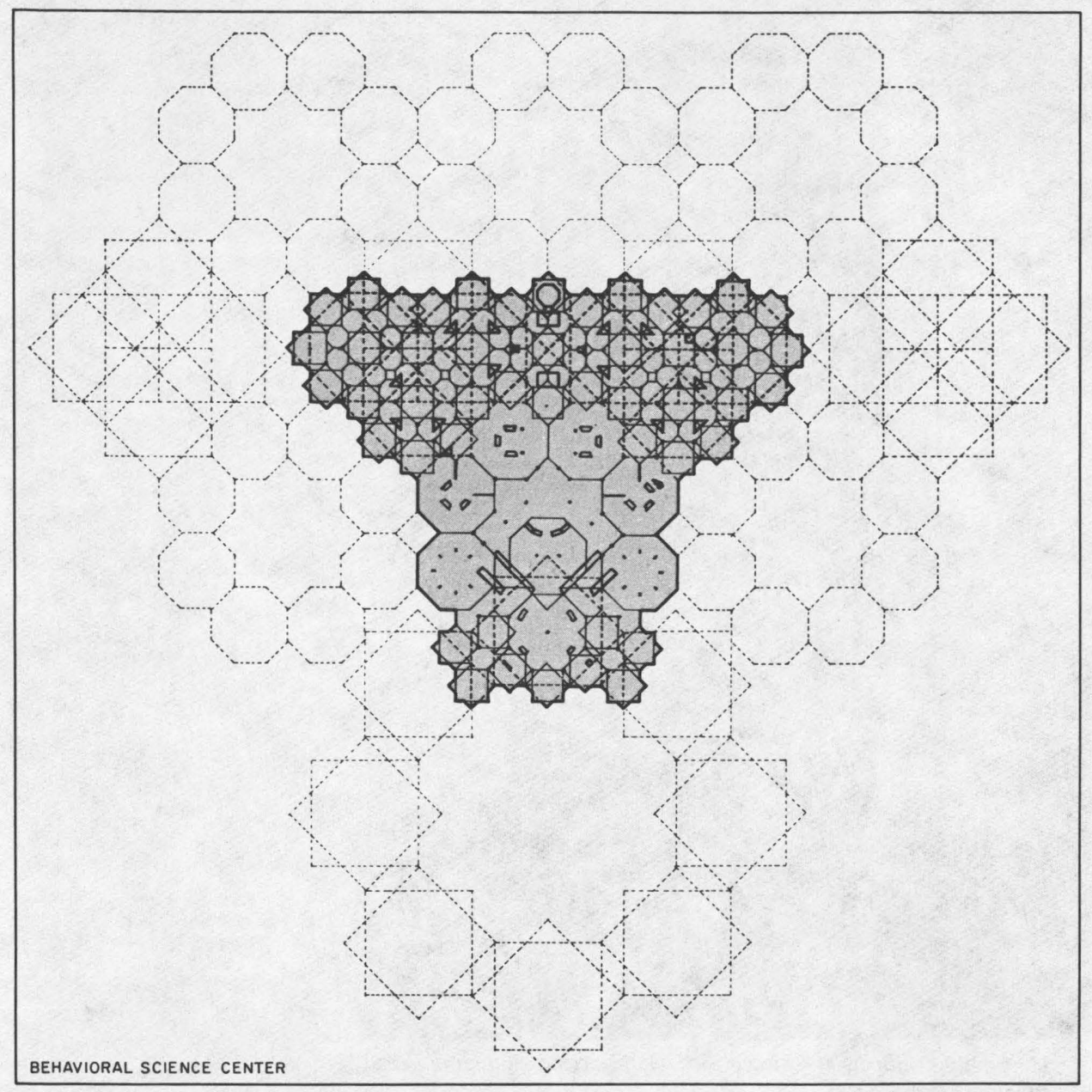

Source: Architectural Record, 167,118 (Jan. 1980).

FIGURE 1

Behavioral Science Center

tion between them and the services floor. A typical floor in one of the towers contains enclosed and open carrels, typing rooms, and seminar rooms arranged around a radial stack system and a central study area. (See figure 2 and photographs 5,6 .) Instead of generating the layout by rotating the square as field theory would require, Netsch has placed a circle within a square, and repeated the pattern in each tower. This opposition of orthogonal and circular forms give the layout a vibrating quality, the viewer's eye moving from circle, to rectangle, to square.

According to an article in the journal Interiors, ${ }^{4}$ Netsch designed Northwestern University's library while he was still formulating his field theory. The building contains, nonetheless, many features of field theory buildings, a "crystalline surface skin," a "lack of facade," "'avoidance of masses," a "contact between interiors and landscape," and "avoidance of disrupting the landscape." 


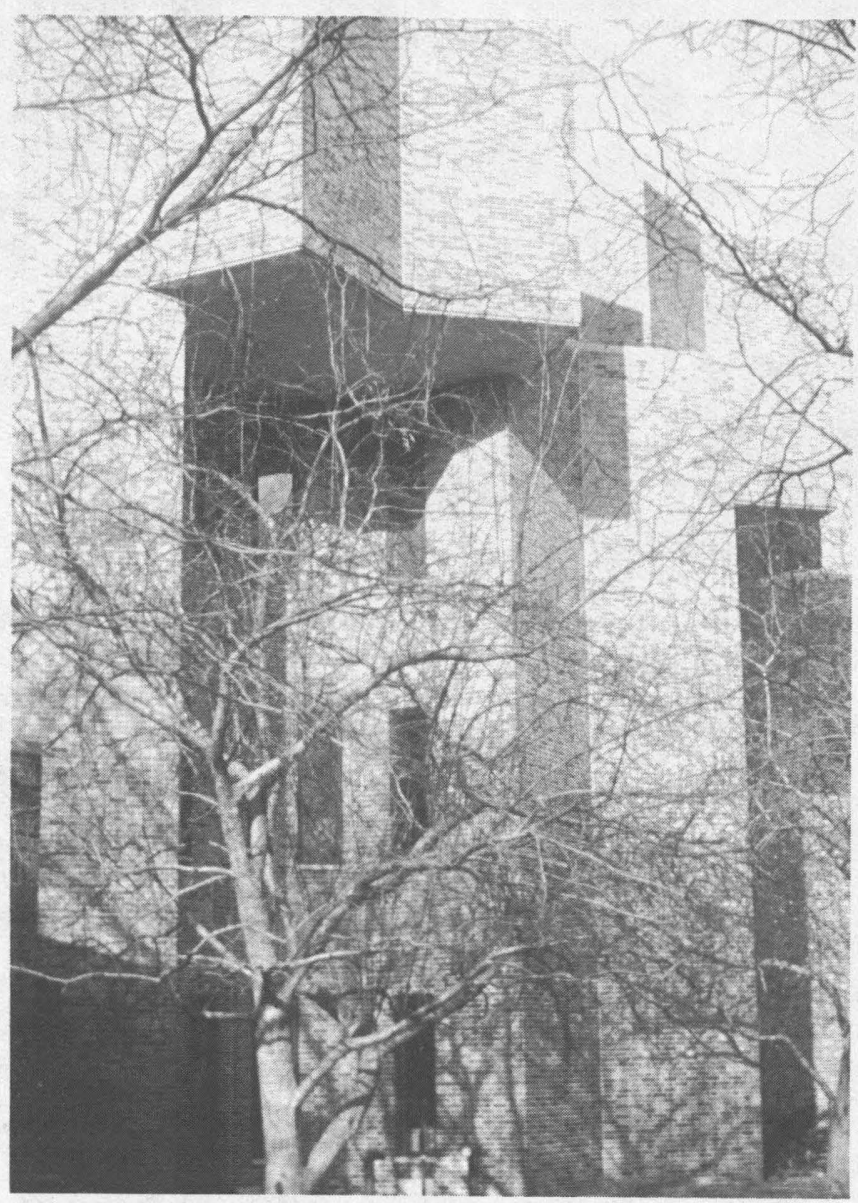

1. University of Illinois at Chicago. Behavioral Sciences Building. View from the South.

Because of the radial arrangement of the stacks, the library user inside the towers is more aware of circular elements in the design than of the orthogonal. Users may initially have difficulty orienting themselves within this layout. Windows are often helpful in assisting users to orient themselves within buildings. In this building, however, windows are small, vertical panels that are not readily visible from within the stacks. For orientation, users must rely on maps, directional arrows, and signage to find their way through an interior apparently devoid of orienting cues. There are cues, however, and they become more apparent by looking at the layout.

Each tower floor has a principal entry approached from the corridor linking it to the service core. Fire exits and stairs to other floors lie opposite the entry in another corner of the tower. A person at the center of a tower can see entry and stairs, but they are easily seen only from the center. Unless the user knows the layout thoroughly, the most efficient way to find a call number location is to move to the center of the tower and use the range finders there to guide his movement along the radial arms. 


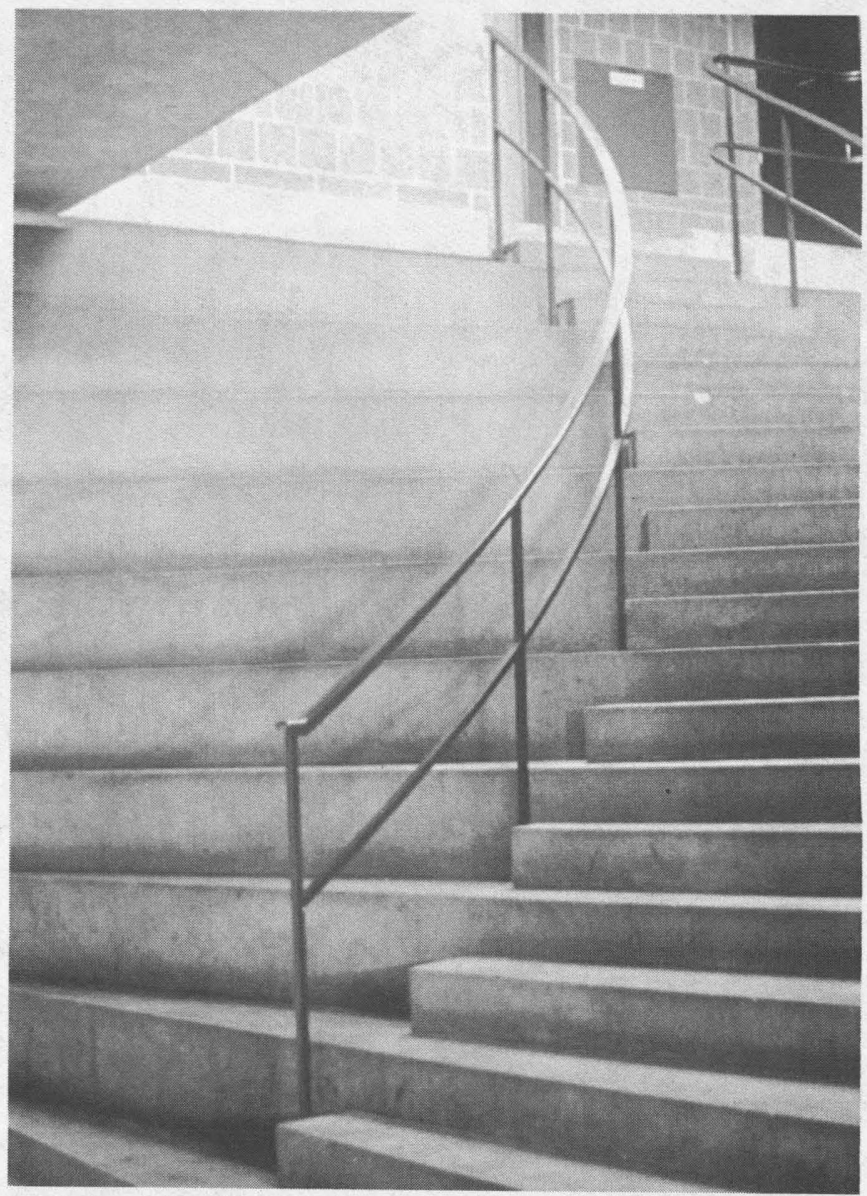

2. University of Illinois at Chicago. Behavioral Sciences Building. Winding Stairway.

This layout takes time to learn. Users accustomed to libraries with orthogonal layouts (and other high-use buildings like supermarkets and department stores) will have to use the building several times before they can move about it comfortably. The radial plan of the stacks permits open carrels and study spaces to be placed near the centers of the towers between the less densely arranged stack ranges, but the radial arrangement doesn't offer as great a density of shelving as an orthogonal layout would. Before the introduction of the online catalog made the placement of terminals closer to the collections possible, the unfortunate user needing to return to the card catalog from one of the towers faced a long and time-consuming trip. This need remains for that portion of the catalog not converted to machinereadable form.

Netsch designed a second library building for Northwestern University, the Seeley G. Mudd Library for Science and Engineering (SEL, 1977). This 60,000square-foot building unites collections for astronomy, biology, chemistry, physics, and engineering. Only collections for geology and mathematics remain separate. The Geology Library lies at the south end 


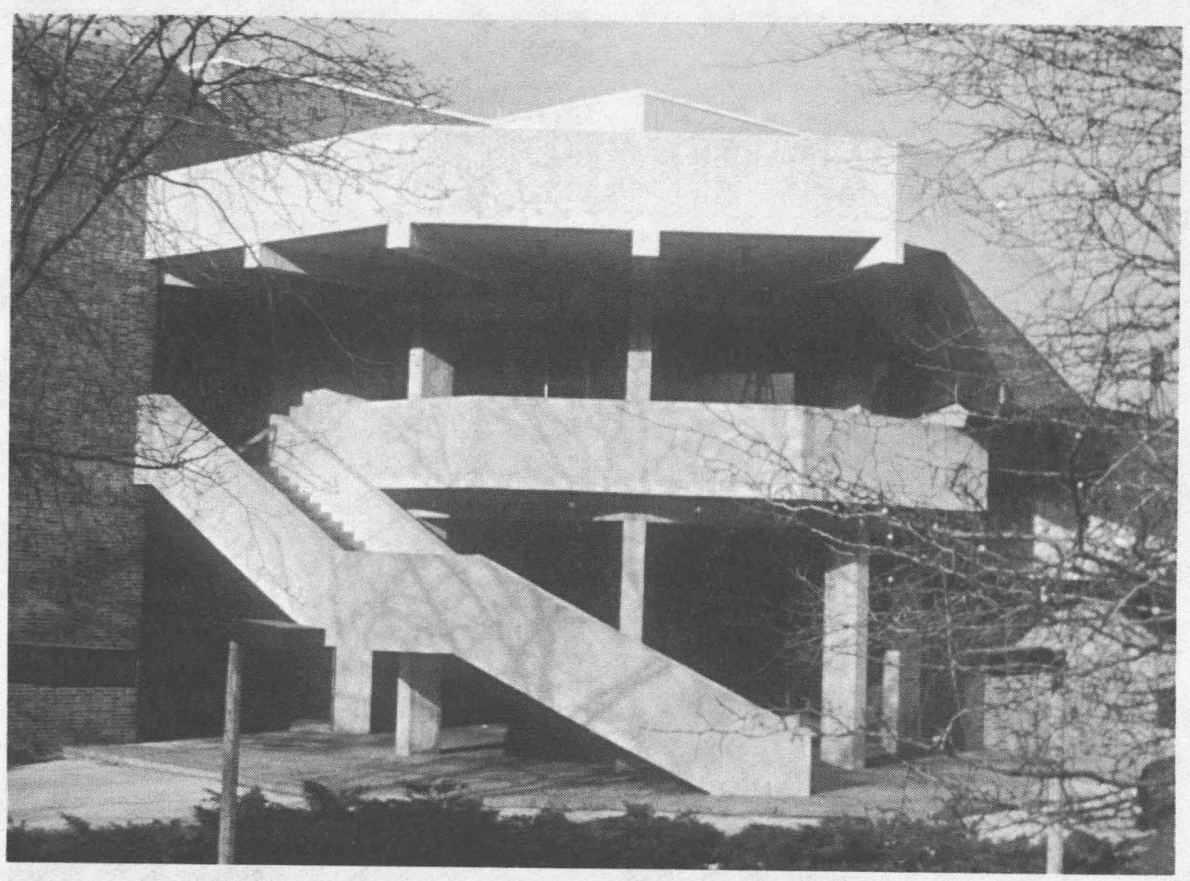

3. University of Illinois at Chicago. Behavioral Sciences Building. Exterior Stairway.

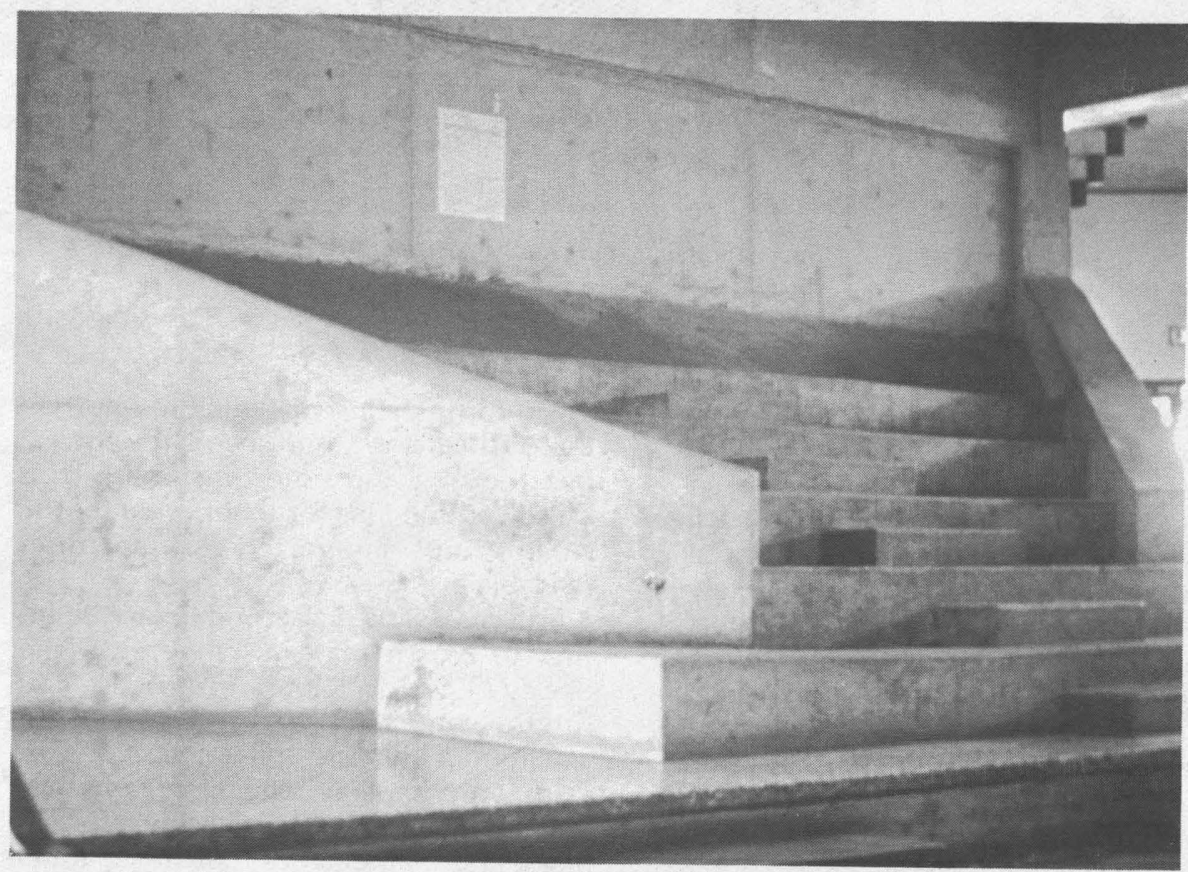

4. University of Illinois at Chicago. Behavioral Sciences Building. Stairs Ascending to Wall. 


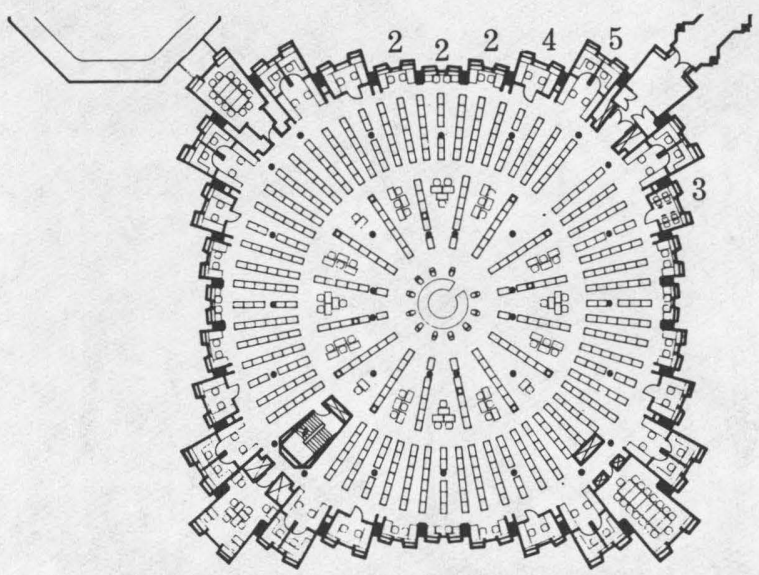

FIGURE 2

South Pavilion

Source: Interiors, 130,110 (Nov. 1970).

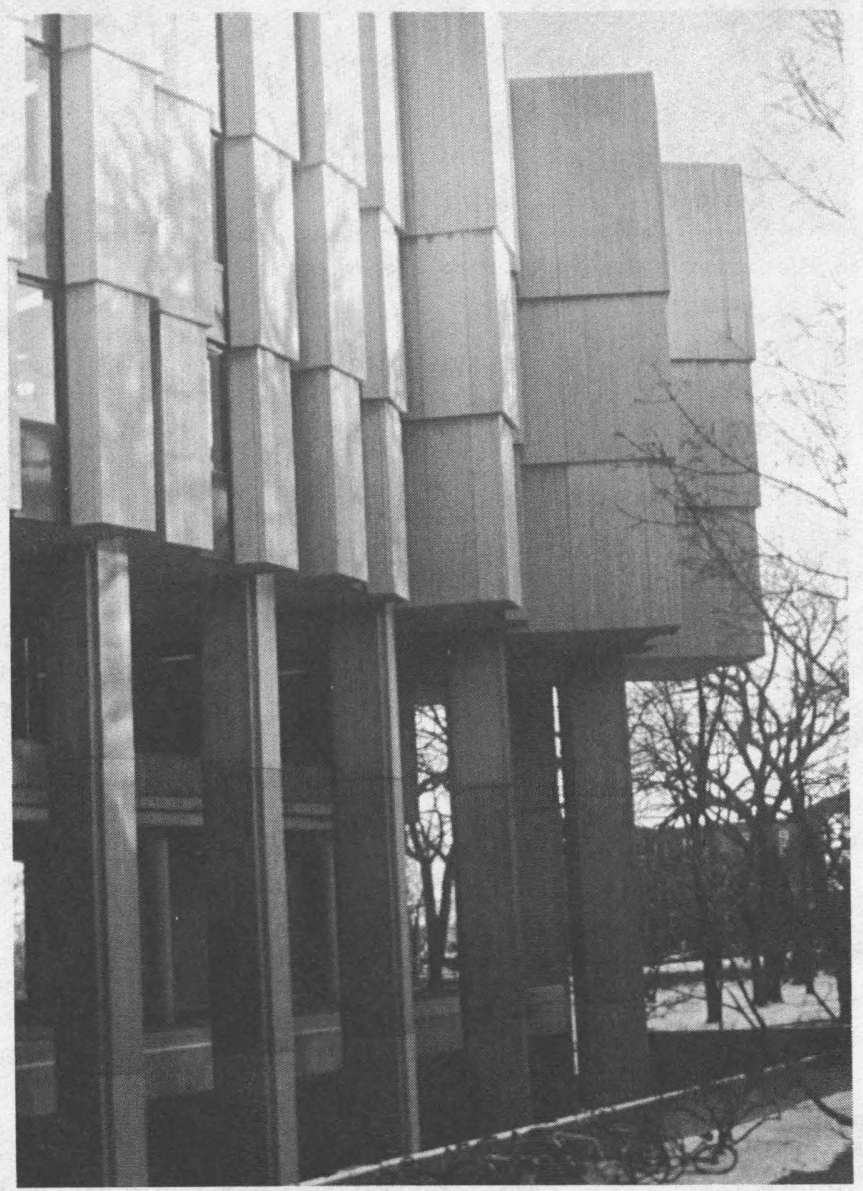

5. Northwestern University Library. Stack Tower. 


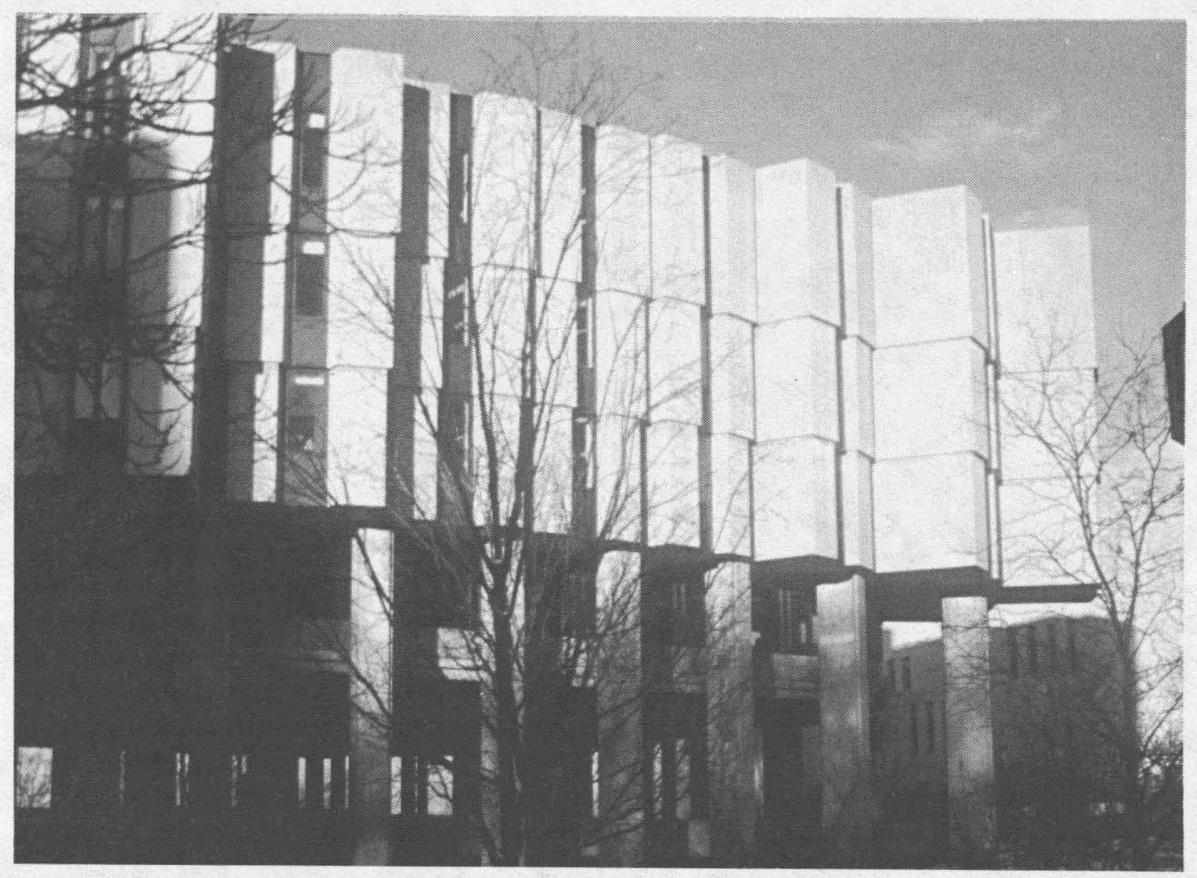

6. Northwestern University Library. Stack Tower.

of campus and will merge with SEL should the geology faculty ever acquire its own space closer to the other sciences in the north.

In SEL, Netsch used rotated squares to define interior spaces (offices, stairwells, mechanical rooms, toilets) while leaving the L-shaped exterior almost completely orthogonal (a diagonal window wall bridges the two arms of the "'L.") (See figure 3, photograph 7.) Early proposals for the building followed field theory principles by extending interior diagonals to the perimeter where triangular insets in the side of the building would have broken up the otherwise unrelieved expanse of limestone and reflective glass. Another discarded variation would have resulted in finlike projections extending beyond the core of the building, set directly opposite the triangular insets. The projections would have contained windows with operable sash, installed for the purpose of improving natural ventilation should air conditioning, as an energy-reducing measure, have to be limited. These projections would have related SEL visually to another nearby Netsch building, the O.T. Hogan Biological Sciences Laboratory. (See photograph 8.)

Users enter SEL on the second, or services floor via a bridge leading from the adjacent Technological Institute Building. An elevator and three stair cores provide convenient access to collections on the first and third floors. Stacks follow a conventional orthogonal layout. Service points are few. Exit control, circulation, and information desks are staffed during hours of heaviest use. These service points are close to each other and are visible from the library entrance. During hours of low use, all three services can be offered from the circulation desk.

Site planning for SEL was constrained by the need to provide access to a major campus drainage system crossing the site. Netsch met this requirement by creating an oversized loading dock at the ground level underneath the second floor main entrance. The layout of the dock and its adjoining mail room preserves some of the 


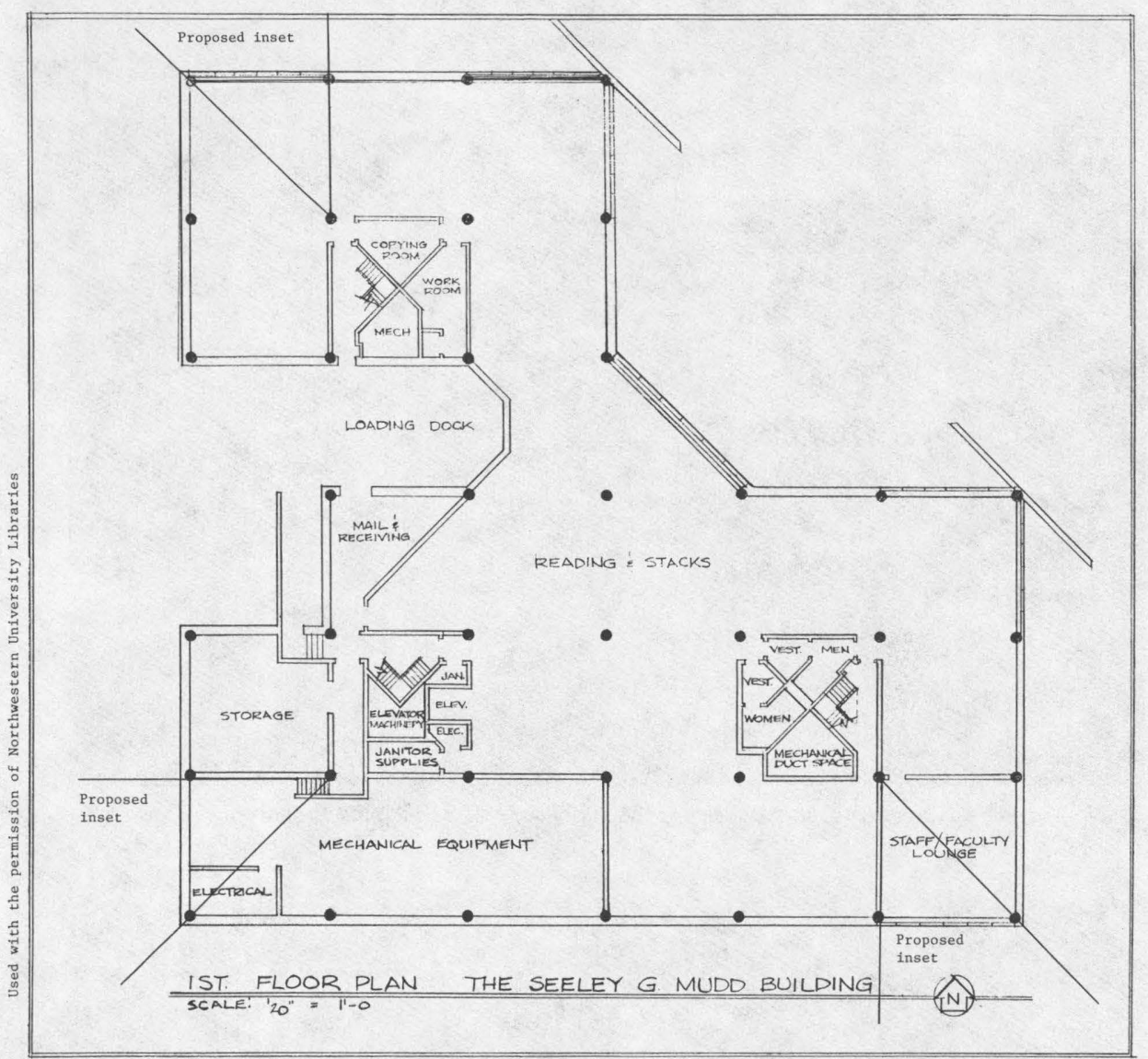

FIGURE 3

Netsch's Rotated Squares Defined Offices, Stairwells, Mechanical Rooms, and Other Interior Spaces

diagonal elements used elsewhere in the building. (See figure 4, photograph 9.) However, the allocation of a significant block of first floor area to dock, heating and ventilating equipment, and staff room breaks up the stack space into isolated pockets that are approachable only by following a somewhat circuitous path.

Netsch often placed doors and corridors near supporting columns, gaining additional space for open areas. This arrangement improved the ratio between net assignable and gross square feet, but it did so at the cost of requiring traffic to move awkwardly around pillars.

Netsch's field theory buildings have ex- terior shapes that follow the interior diagonals generated by the rotated squares. The curious feature about the application of these diagonals is that the geometric and aesthetic unity resulting from the design is not apparent to those using the building. The organic nature of the design is only revealed by viewing the layout from above, as if the roof were cut away. Also, applying the system of rotated squares to the layout in SEL forced departures from the specifications of the program of requirements. For example, offices are about 90 square feet instead of the specified 140 square feet. The oddly shaped and reduced-in-size offices re- 


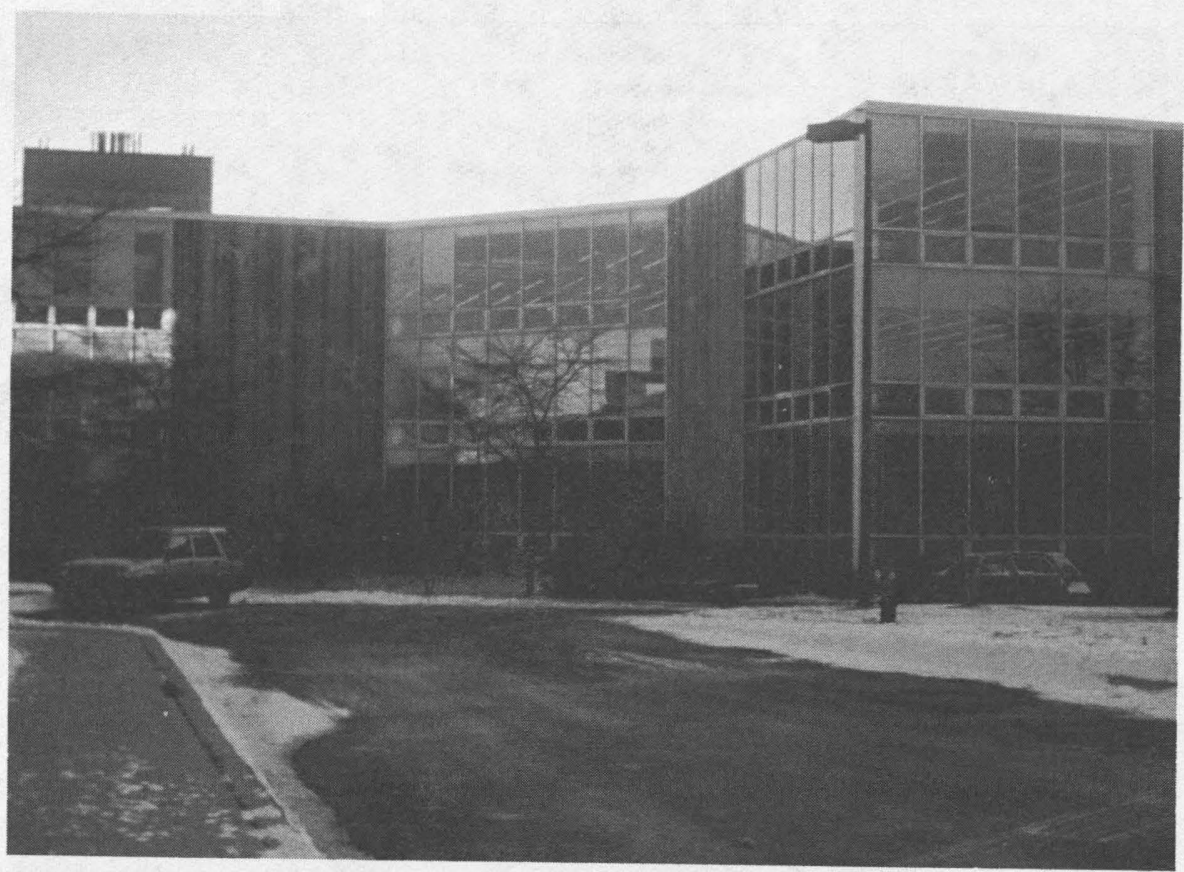

7. Northwestern University Library. Seeley G. Mudd Library for Science and Engineering.

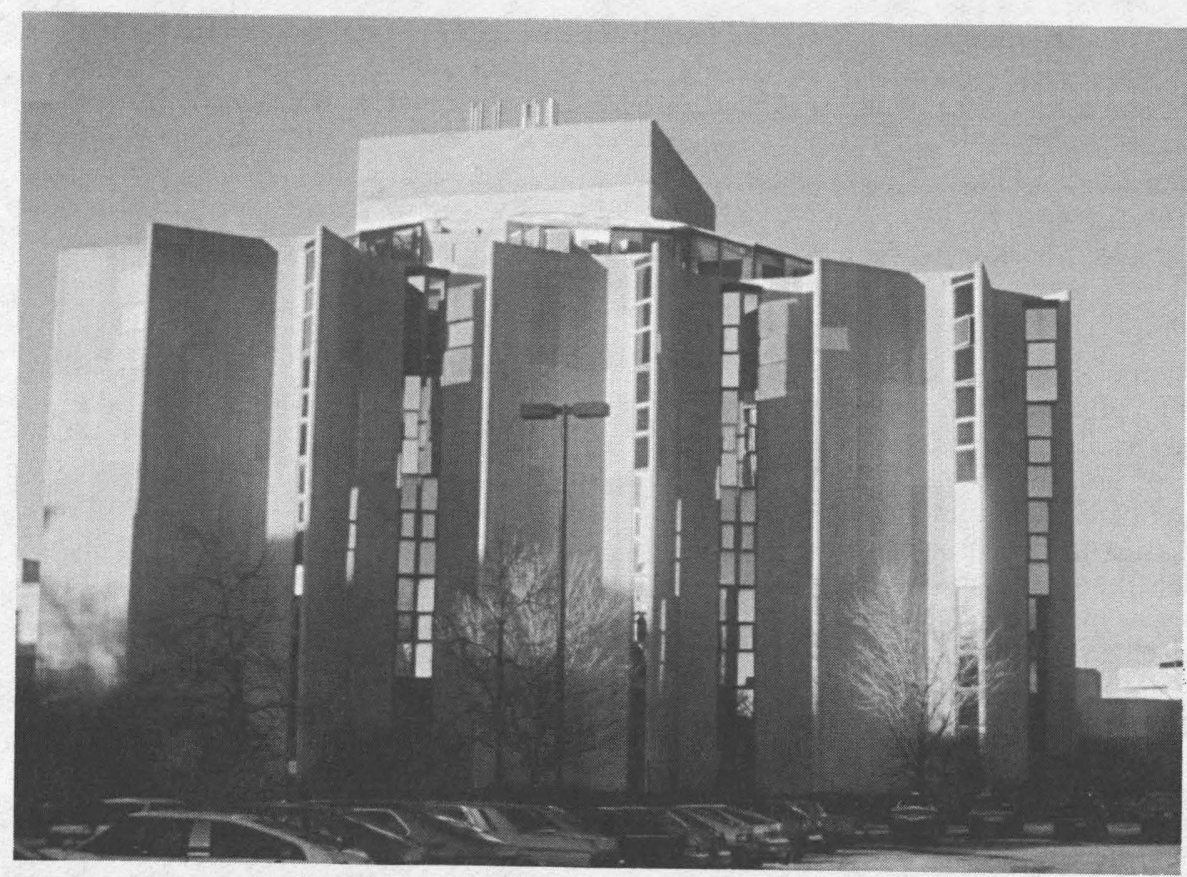

8. Northwestern University Library. O. T. Hogan Biological Sciences Building. 


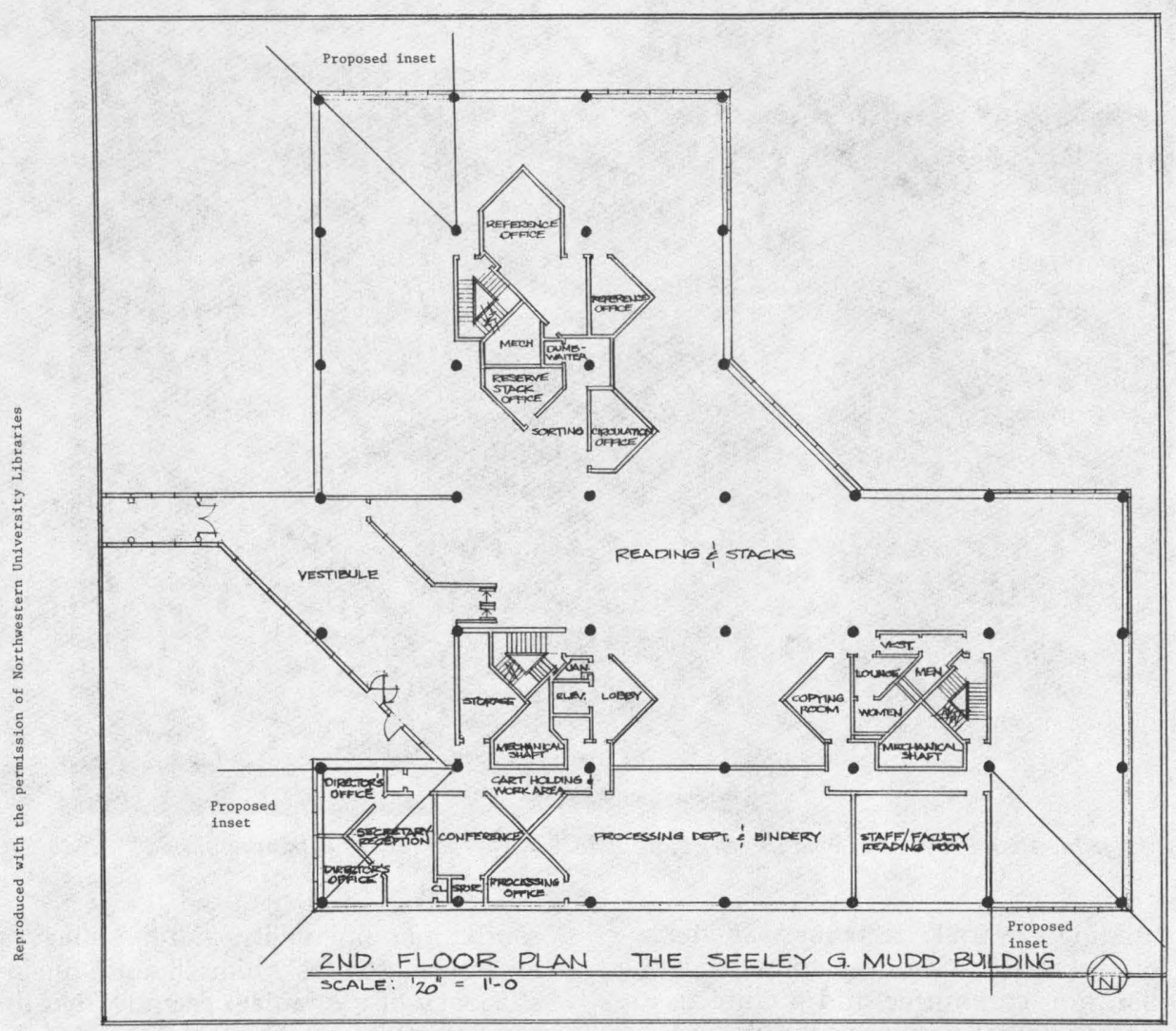

FIGURE 4

Level Two: User Services

quire special furniture. Wall units must be used because conventional rectangular desks are both too large and do not fit easily into the unusual offices.

When the planning committee finally decided that the building exterior should not be punctuated by triangular insets, Netsch proposed retaining triangular areas as clerestories, with balconies that would link one floor to another. In these attempts to bring visual interest to the building, to "get away from the boredom of the square box, ${ }^{\prime \prime}$ Netsch argued that flooring and enclosing the triangular areas would add to the building's construction costs, because such spaces had to be heated, cooled, and lit. The planning committee countered that balconies would result in unwanted noise being transmit- ted between the floors and that too much usable space would be lost to features that were solely of aesthetic interest. As built, the library contains no triangular insets, fins, or balconies. These changes produced a less distinctive design, but one more closely meeting the functional goal of the planning committee to maximize square footage at the lowest cost. Netsch has called the library a "compromise" building.

SEL offers staff and users generous public areas, large windows looking out over Northwestern's north campus and Lake Michigan, and conveniently placed service desks. Its undersized, oddly shaped offices, fragmented ground floor, and oversize loading dock are awkward details, but do not significantly reduce the 


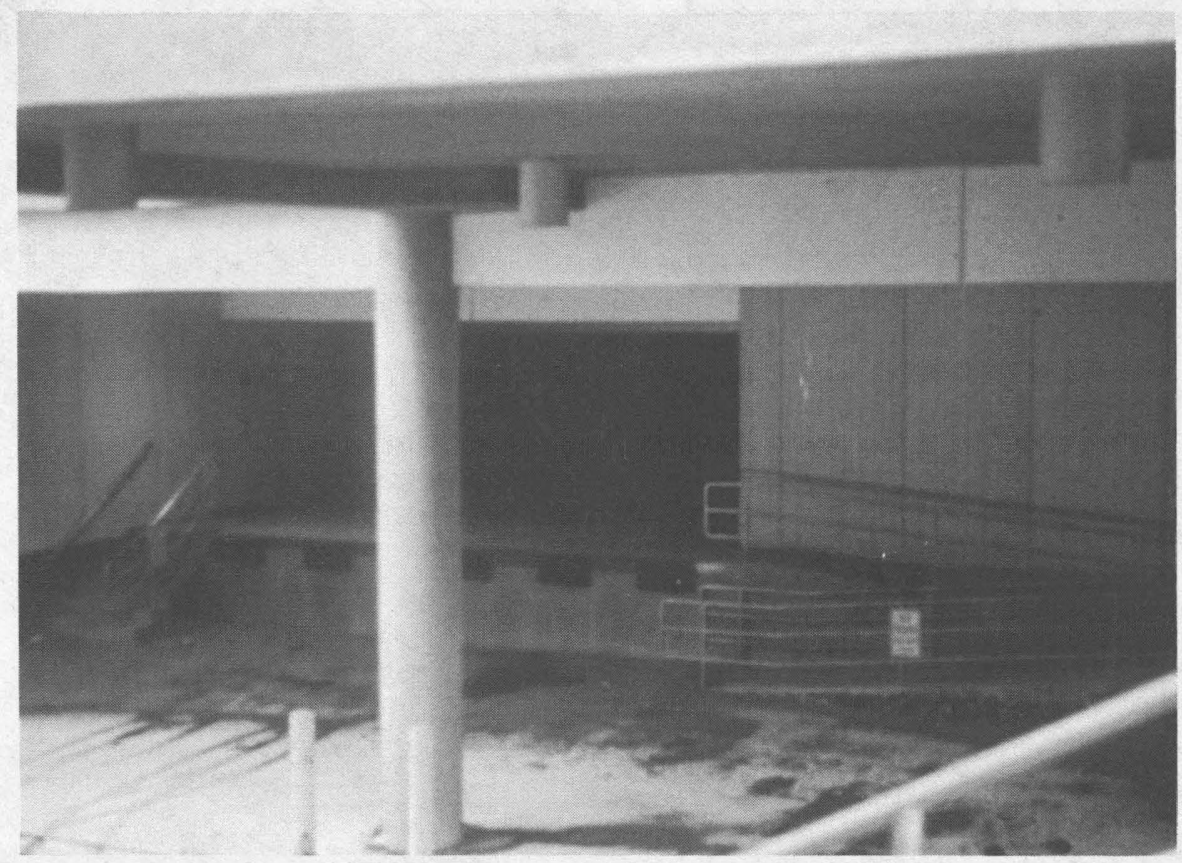

9. Northwestern University Library. Seeley G. Mudd Library for Science \& Engineering. Dock.

building's overall effectiveness. Better solutions might have been found, but the planning committee and architects expended considerable energy in debating the functionality of the diagonal layout, and further changes could not have been made without starting almost entirely anew.

'Potential flaws,' include the use of irregular shapes, interior or exterior courts, monumentality, and too much or too little glass."

\section{CONCLUSION}

In his 1984 College $\mathcal{E}$ Research Libraries article, David Kaser uses four problem areas identified by Keyes Metcalf to critique library buildings constructed during the previous two decades. ${ }^{6}$ These problem areas, "potential flaws," include the use of irregular shapes, interior or exterior courts, monumentality, and too much or too little glass. Kaser himself notes the inefficiency of the radial design for Northwestern's Library. This building, visually appealing on the exterior and elegantly finished on the interior, requires its users to traverse considerable distances from entrances to towers. The self-contained towers admit no possibility of expansion; once filled the only alternative will be another free-standing structure. A large plaza that also serves as a roof to the public services and office floor has been a perpetual source of leaks, the result of fissures opening between plaza and independently moving towers. The reasons for citing irregular shape and monumentality as sources of problems are demonstrated in this building.

In a "field theory" building like the Behavioral Sciences Building, Netsch showed that he could manipulate geometric forms generated by rotated squares in a variety of ways to create an aesthetically unified architectural work. However, its negative features include a bewildering 
layout, poorly illuminated interiors unrelieved by the use of color, and fanciful winding staircases, those on the exterior closed to use during Chicago's harsh winters. In sum, BSB is a maze of confusing, interior corridors and awkwardly shaped offices. Like NU's towers, a lack of windows and a confusing layout offer users few cues by which to orient themselves. BSB's west face is forbidding and unwelcoming to traffic from adjacent parking lots. (See photograph 10.) Its brick and concrete surfaces, alternating gray and brown, both interior and exterior, give it a cold, austere appearance.

Had Netsch applied the rigid geometry characteristic of his other buildings to Northwestern's Science-Engineering Library, the design would have dominated and subordinated the function taking place within it as it does in the other buildings discussed in this paper. That outcome was avoided in SEL because the planning committee decided that recovery of functional space was more important than the creation of a distinctive and aes- thetically unified design.

The characteristics of the buildings described in this paper and their impact on users are by no means unique, but thoughtful consideration of the design features exhibited in these building designs suggests other areas of inquiry: What are the costs in user satisfaction and functional utility in buildings where design governs so thoroughly? Does the use of "You-Are-Here Maps" 7 contribute to the aesthetic appreciation of a building as well as its effective use? Must users of complicated buildings develop an understanding of the logic underlying the layout before they begin to find their way in them effectively? Do users conceptually map a building to obtain most effective use of it?

The creation of an academic library building meets more goals than the construction of a structure. These include the goals of architects to create buildings of beauty, to lend distinction to the names of their firms (and that lead to other commissions); the goals of librarians to occupy buildings of function and comfort for

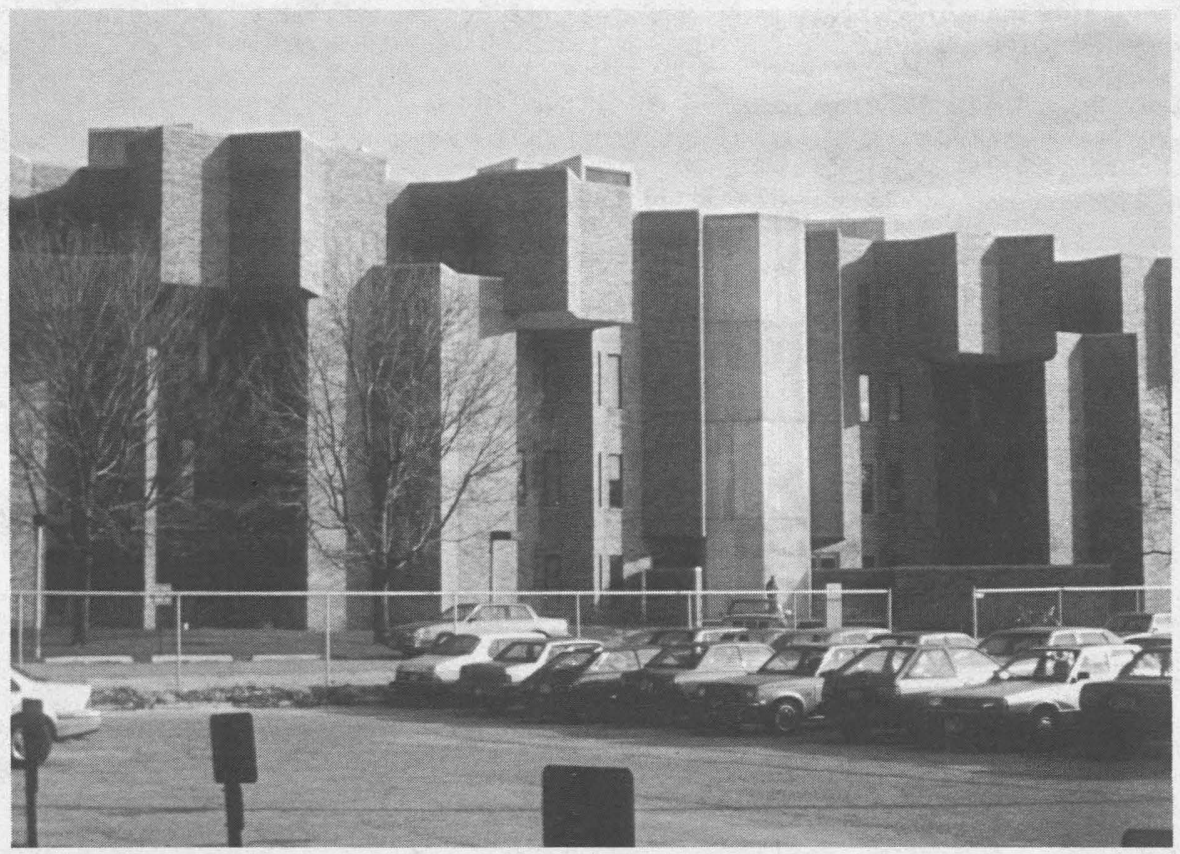

10. University of Illinois at Chicago. Behavioral Sciences Building. View from the West. 
themselves and their users (and that enhance their reputations as professionals of both vision and practicality), and the goals of administrators to complete buildings that satisfy those who sponsor, support, and lend their names to the buildings and campuses on which the buildings are placed.

Librarians who become involved in building planning can prepare themselves for working with architects designing buildings for them by visiting and reviewing layouts for other buildings designed by the architects. In working with prominent architects, librarians will be able to determine whether the architects have written about the aesthetic principles informing their work. They may ask questions like the following: Will those working in and using the building be able to move about in it without excessive reliance on signage, floor plans, or informa- tion desks? Will standard furniture and equipment fit in the spaces designed for them? Will users, book trucks, cartons and crates be able to move or be moved easily from one area or one floor to another without encountering columns, balconies, or other impediments? Is there so little glass that users will become confused or disoriented within the building, or so much that valuable collections will be exposed to harmful sunlight?

Librarians need to be alert to the consequences of accepting designs that depart from conventions by which much of the world uses and judges buildings, and they should ask themselves how the design promotes the use to which a building will be put. Finally, they should remember that academic library building planning is very much a group process in which the outcome may change, even late in the project.

\section{REFERENCES}

1. Carl W. Condit, Chicago 1930-1970: Building Planning, and Urban Technology (Chicago: University of Chicago Press, 1974) p.181-89.

2. "A New Museum by Walter Netsch of SOM Given Order by His Field Theory," Architectural Record, 167:111-20 (Jan. 1980).

3. Ibid., p.118.

4. Gueft, Olgo, "Walter A. Netsch" Interiors, 130,110 (Nov. 1970).

5. "Netsch, Walter A(ndrew Jr.)," In Contemporary Architects, ed. by Muriel Emanuel (New York: St. Martin's Press, 1980), p.585-86.

6. David Kaser. "Twenty-five Years of Academic Library Building Planning," College \& Research Libraries, 34:261-68 (July 1984).

7. Marvin Levine, "You-Are-Here Maps: Psychological Considerations," Environment and Behavior 14, no.2:221-37 (March 1982). 